\title{
A rare case of unruptured tubal ectopic pregnancy at 14 weeks gestation with live foetus in situ and review of literature
}

\author{
Jayanta K. Biswas ${ }^{1 *}$, Vivek Tewari \\ ${ }^{1}$ Department of Obstetrics and Gynaecology, ${ }^{2}$ Department of Radiodiagnosis, Military Hospital, Pathankot, Punjab, India
}

Received: 13 November 2020

Accepted: 15 December 2020

\section{*Correspondence:}

Dr. Jayanta K. Biswas,

E-mail: jayantabiswas1977@gmail.com

Copyright: $(\odot$ the author(s), publisher and licensee Medip Academy. This is an open-access article distributed under the terms of the Creative Commons Attribution Non-Commercial License, which permits unrestricted non-commercial use, distribution, and reproduction in any medium, provided the original work is properly cited.

\begin{abstract}
Ectopic pregnancy is a condition, where the fertilized ovum implants anywhere other than normal uterine cavity. It is life threatening emergency condition and it can present in diverse ways. More than $95 \%$ of ectopic pregnancies usually occur in fallopian tube, ampulla being commonest site of tubal ectopic pregnancy. Diagnosis with location of pregnancy is usually possible by ultrasonography in 1st trimester. However, in most of the developing countries with limited resources, many women do not undergo ultrasonography and medical examination in early pregnancy, leading to late diagnosis. It may lead to life threatening presentation of ectopic pregnancy. Reported average duration of diagnosis of unruptured tubal ectopic pregnancy is usually between 5 to 9 weeks of gestation. Very rarely tubal ectopic pregnancy can remain asymptomatic and unruptured for longer than this usual period of gestation. The reported case is a rare case of viable, unruptured tubal ampullary ectopic pregnancy of 14 weeks of gestational age.
\end{abstract}

Keywords: Tubal pregnancy, Unruptured, Ampullary

\section{INTRODUCTION}

Implantation of the fertilized ovum anywhere outside the normal endometrial cavity is defined as ectopic pregnancy. It is one of the most common dreaded obstetric condition in early pregnancy. ${ }^{1}$ The majority of ectopic pregnancy are in the fallopian tube; ampulla being commonest site (around 70\%). Other less common tubal ectopic sites are fimbrial, isthmic and interstitial. ${ }^{2}$ There are many risk factors associated. Presentations vary from being asymptomatic to hemodynamic instability. Tubal pregnancies usually rupture between 5th to 9th week gestation and may result in significant haemorrhage and shock. ${ }^{3}$ It is extremely rare for tubal ectopic pregnancy to present at 2nd trimester as asymptomatic. The reported case is of viable unruptured ampullary ectopic pregnancy presented at 14 weeks gestation.

\section{CASE REPORT}

A 21 years old patient with Gravida 2 para 1 living 1 status with 3 and $1 / 2$ months amenorrhea was transferred from primary care level hospital located at hilly area to a secondary care level hospital with pain abdomen of a few hour duration. She had regular menstrual cycle and had previous caesarean section delivery 2 years back for breech presentation. This was her 1st Antenatal visit to a Gynaecology centre in this pregnancy. She had done a few very basic investigations before but ultrasonography was not done. She had no specific identifiable risk factors for ectopic pregnancy other than history of previous laparotomy for lower segment caesarean section (LSCS). She had no pain abdomen on arrival at referred hospital, and her basic vital parameters were normal like pulse rate74 beats per minute, blood pressure recorded 108/78 mm of $\mathrm{Hg}$ with no pallor. 
On obstetric examination, $6-8 \mathrm{~cm}$ suprapubic firm abdominal mass with restricted mobility was palpable. Per speculum examination showed closed cervical os with no bleeding. Bimanual examination suggested bulky uterus with cervical motion tenderness and a palpable $8 \times 8 \mathrm{~cm}$ right adnexal abdomino-pelvic mass.

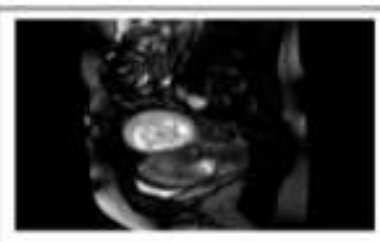

(A)

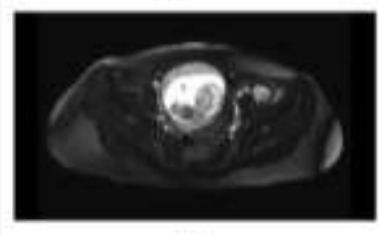

(c)

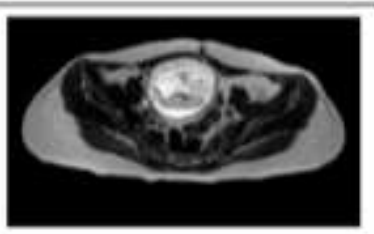

(ii)

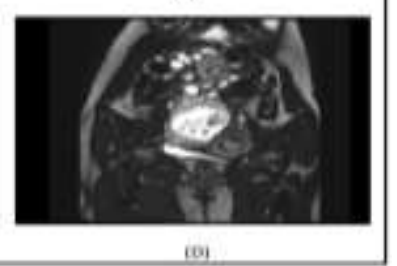

Figure 1: Multiplanar MRI images depicting large viable right tubal pregnancy.

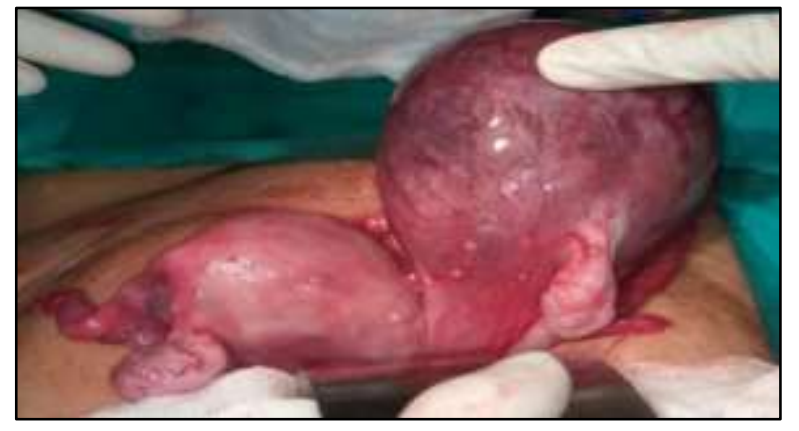

Figure 2: Right sided unruptured viable ectopic pregnancy with bulky uterus.

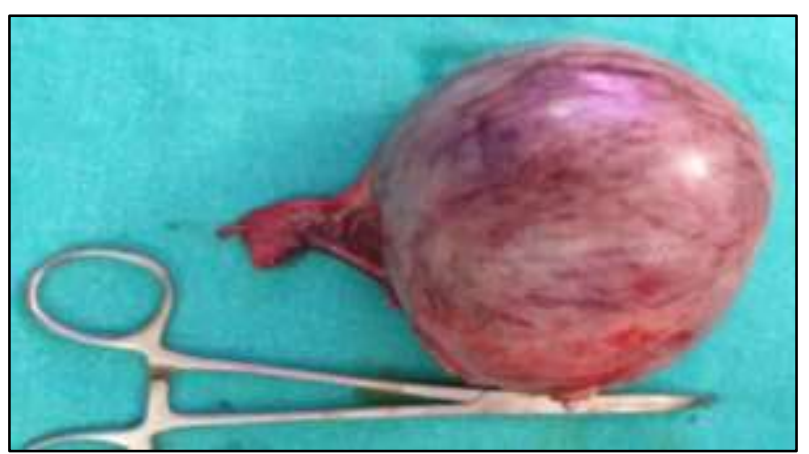

Figure 3: Right sided salpingectomy specimen.

Transabdominal sonography (TAS) and transvaginal sonography (TVS) revealed bulky uterus with thick endometrium, a 14 weeks live ectopic pregnancy in right adnexa separated from right ovary, but not able to locate exact site mainly to rule out interstitial or cornual location. Few basic investigations were sent. Magnetic resonance imaging (MRI) was asked to locate exact location of tubal ectopic pregnancy. It revealed a live ectopic pregnancy in right tube away from cornu or interstitial region of tube (Figure 1). Patient's haemoglobin was $11.2 \mathrm{gm} \%$ and blood group- 'A' positive with normal liver and renal function tests. 2 units of whole blood demand was placed and written informed consent was taken for exploratory laparotomy after explaining her all possible intra-operative and post-operative complications. Intra-operative findings were- bulky uterus, omental adhesions to anterior and right side of uterus, $8 \times 7 \mathrm{~cm}$ right tubal mass with adhered right ovary with right fallopian tube (Figure 2). Right sided salpingectomy was performed after omental adhesiolysis and separation of right ovary from the tubal mass. Left sided adnexal structures were healthy and normal looking. Right tubal mass was sent for histopathological examination (Figure 3), which confirmed tubal gestation sac with foetal size corresponding 14 weeks gestation and placenta as well.

\section{DISCUSSION}

Ectopic pregnancy is an important cause of obstetric morbidity and mortality in 1 st trimester. ${ }^{4}$ Ampullary part of fallopian tube is the commonest site $(73 \%)$ as per Bouyer et al. ${ }^{2}$ Risk factors for ectopic pregnancy include advanced maternal age, smoking, history of infertility and treatment with in-vitro fertilization, past ectopic pregnancy, tubal infection, prior abdominal or pelvic surgery. ${ }^{5}$ Incidence of ectopic pregnancies is increasing mainly due to increase in sexually transmitted diseases and accessibility of advanced infertility managements. ${ }^{2}$ Most of women with ectopic pregnancies are not having any identifiable risk factor.

Ruptured ectopic pregnancies are clinically easily diagnosed but diagnosing it at unruptured state is difficult. ${ }^{6}$ TVS helps to identify the site of pregnancy and even ectopic pregnancy at an early stage. More accurate diagnosis is possible with combination of TVS and serum estimation of beta subunit of human chorionic gonadotropin $\left(\beta\right.$-hCG). ${ }^{7}$ Diagnosis through TVS of an undisturbed tubal pregnancy is reliable and usually commonly diagnosed at 5 to 9 weeks gestation. Presence of adnexal gestational sac alongside fetal pole with cardiac activity is considered as the most definitive sign of ectopic pregnancy, but is only seen in $10-17 \%$ cases. $^{8}$ Absence of sub-mucosal layer within the wall of fallopian tube allows fertilized ovum for implantation within the musculature and rapidly proliferating trophoblasts erode through the muscularis layer and tubal rupture results at 5 to 9 weeks gestation. ${ }^{2}$ Early diagnosis of ectopic pregnancy can be missed and patients may report in emergency with tubal rupture as per Cisse et al. ${ }^{9}$ A few cases of ectopic pregnancies at advanced gestational age were reported. ${ }^{10,11}$

Interstitial or cornual pregnancies can progress into late 1st or early 2nd trimester. ${ }^{12}$ Interstitial pregnancies are uncommon and accounts for 2-4\% cases of all ectopic pregnancies and cornual pregnancy are even rarer (1\% of all ectopic pregnancies). ${ }^{12,13}$ These pregnancies usually 
occur when the gestational sac implants in the intramyometrial segment of the fallopian tube. Due to the increased distensibility of this segment, interstitial pregnancies can grow till 16th week gestation and its rupture may lead to life threatening haemorrhage due to proximity of fallopian tube and uterine artery. In TAS/TVS of an interstitial pregnancy, an eccentrically located gestational sac is surrounded by a thin layer of myometrium, measuring $<5 \mathrm{~mm}$. Most of the times, it is difficult to interpret. A more specific finding is the presence of 'interstitial line sign' (an echogenic line that extends into the upper regions of the uterine horn and borders the margin of the intramural gestational sac), probably representing the interstitial part of fallopian tube. ${ }^{14}$ In the case reported, ultrasonography was inconclusive regarding exact location of ectopic pregnancy, hence MRI was done to rule out more catastrophic interstitial pregnancy.

Medical management or conservative tubal surgeries like salpingostomy may be offered for early diagnosed unruptured ectopic pregnancy to achieve successful future pregnancy outcome. ${ }^{15}$ Major complications can set in due to late diagnosis of ectopic pregnancy and needs surgical intervention; total salpingectomy being the surgery of choice for advanced tubal pregnancy.10 Thus, in the case reported total right sided salpingectomy was performed.

\section{CONCLUSION}

There has been significant rise in the incidence of ectopic pregnancies ever since 1970s. Ectopic pregnancy should always be considered in women of child bearing age who present with early pregnancy problems like lower abdominal pain or irregular vaginal bleeding. Advanced tubal ectopic pregnancy is rare unless implanted in interstitial/cornual part. Awareness of risk factors and serial trans-vaginal ultrasonography coupled with serial serum $\beta$-hCG doubling time estimation allows for early diagnosis and management for ectopic pregnancy. Moreover, women should be encouraged and educated to seek medical attention whenever they miss their menstrual periods. Timely diagnosis and management will help to reduce life threatening maternal morbidity and mortality related to ectopic pregnancies and also to restore fertility.

\section{Funding: No funding sources}

Conflict of interest: None declared

Ethical approval: Not required

\section{REFERENCES}

1. Murray H, Baakdah $\mathrm{H}$, Bardell $\mathrm{T}$, Tulandi $\mathrm{T}$. Diagnosis and treatment of ectopic pregnancy. CMAJ. 2005;173(8):905-12.
2. Bouyer J, Coste J, Fernandez H, Pouly JL, Job Spira N. Sites of ectopic pregnancy; a ten year population based study of 1800 cases. Hum Reprod. 2002;17(12):3224-230.

3. Saxon D, Falcone T, Mascha EJ, Marino T, Yaom M, Tulandi T. A study of ruptured tubal ectopic pregnancy. Obstet Gynecol. 1997;90(1):46-49.

4. Grimes DA. The morbidity and mortality pf pregnancy. Am J Obstet Gynecol. 1994;170(5pt20):1489-494.

5. Radaelli T, Bulfamente G, Cetin I, Marconi AM, Pardi G. Advanced tubal pregnancy associated with severe fetal growth restriction; a case report. J Matern-Fetal Neonatal Med. 2003;13:422-25.

6. Kirk E, Bourne T. Diagnosis of ectopic pregnancy with ultrasound. Best Pract Res Clin Obstet Gynecol. 2009;1-8.

7. Kadar N, de Vore G, Ramcro R. Discriminitory hcg zones; its use in sonographic evaluation of ectopic pregnancy. Obstet Gynecol. 1981;58920:156-61.

8. Condous G, Okaro E, Khalid A, Lu C, van Huffel S, Timmerman D et al. The accuracy of transvaginal ultrasonography of the diagnosis of ectopic pregnancy prior to surgery. Hum Reprod. 2005;1404-409.

9. Marion LL, Meeks GR. Ectopic pregnancy: History, incidence, epidemiology and resk factors. Clin Obstet Gynecol. 2012;55(20):271-74.

10. Nkwabong E, Tincho EF. A case of a 26 weeks ampullary pregnancy mimicking IUD. Anatol J Obstet Gynecol. 2012;1(2):1-3.

11. Sachan R, Gupta P, Patel ML. Second trimester unruptured ampullary ectopic pregnancy with variable presentation: Two unusual cases. IJCRI. 2012;3(8):14.

12. Webb EM, Green GE, Scoutt LM. Adnexal mass with pelvic pain. Radiol Clin North Am. 2004;42:329-48.

13. Dialani V, Levine D. Ectopic pregnancy: a review. Ultrasound Q. 2004;20:105-17.

14. Ackerman TE, Levi CS, Dashefsky SM, Holt SC, Lindsay DJ. Interstitial line: sonographic finding in interstitial (cornual) ectopic pregnancy. Radiology. 1993;189:83-87.

15. Josie L Tenore. Ectopic pregnancy. Am Fam Physician. 2000;61(4):1080-88.

Cite this article as: Biswas JK, Tewari V. A rare case of unruptured tubal ectopic pregnancy at 14 weeks gestation with live foetus in situ and review of literature. Int J Reprod Contracept Obstet Gynecol 2021;10:422-4. 